\title{
Media-médium: entre la etnografía y el cine comunitario
}

\section{Media-medium: Between Ethnography and Communitarian Cinema}

\author{
Carolina Soler ${ }^{1}$ \\ carolinasolerc@gmail.com
}

\begin{abstract}
Resumen
A través de la narración de una serie de experiencias etnográficas de campo vividas durante la realización de cine comunitario con indígenas, la autora propone explorar las implicancias del cine más allá del corte final de la obra producida, e indaga sobre el proceso cinematográfico y las diferentes dimensiones de lo social que lo atraviesan. Los ejes no son ni la cámara ni su operador, sino del proceso mayor de abordar un proyecto cinematográfico comunitario. El final del artículo hace referencia a la expansión del film fuera de sus límites temporales y físicos, a la idea de película en continua realización y a la proyección como performance que completa al filme.
\end{abstract}

\section{Palabras clave}

Cine comunitario, indígenas, trabajo de campo etnográfico, Chaco, Amazonía, Antropología visual.

\begin{abstract}
Through the ethnographic account of a series of field experiences lived during the production of communitarian cinema with indigenous peoples, the author proposes to explore the implications of cinema beyond the final cut of the work and inquiries about the cinematographic process and the different dimensions of the social which cross through it. At the end, she refers to the expansion of the film outside its temporal and physical limits stating that films are in continuous realization and that their projection is a performance which completes them.
\end{abstract}

\section{Keywords}

Communitarian Cinema, Indigenous peoples, Ethnographic Fieldwork, Chaco, Amazon, Visual Anthropology.

1 Magister en Antropología y Etnología EHESS (École des Hautes Études en Sciences Sociales). Becaria doctoral de CONICET (Consejo Nacional de Investigación en Ciencia y Técnica). Doctorante en Antropología en cotutela Universidad de Buenos Aires, Argentina. École des Hautes Études en Sciences Sociales, Francia. Orcid: 0000-0003-3026-2813. 
Forma sugerida de citar: Soler, Carolina (2017). Media-médium: entre la etnografía y el cine comunitario. Universitas, $X V(27)$, pp. 179-194.

A la memoria de Patricio Taish, cineasta y amigo shuar

\section{Introducción}

Hemos escuchado más de una vez la historia de cómo la antropología y el cine han mantenido un estrecho vínculo desde sus orígenes (De Brigard, 2003; Marcus y Ruby, 2011; Ruby, 2000; Ardèvol, 1994). También podría alegarse que el cine se funda en el entusiasmo analítico de algunos fotógrafos -como Eadweard Muybridge y Étienne Jules Marey-por indagar sobre el movimiento tanto de los animales como de los seres humanos. En la primera mitad del siglo XX, los antropólogos que consideraron la cámara como una herramienta para la investigación vieron en el registro mecánico del cine una forma fructífera de conservar imágenes en movimiento de rituales y gestualidades de hombres de culturas lejanas, ante la avanzada de un occidente moderno que amenazaba con llevárselo todo (Bateson y Mead, [1942] 1993). Mead, en su texto Visual Anthropology in a Discipline of Words ([1974] 2003), lanzó una especie de proclama en la que pedía a los antropólogos que tomaran las cámaras registraran horas de rushes sin editar que pudieran servir para revisar meticulosamente, una y otra vez, gestos y conductas de pueblos indígenas. Proponía el registro fílmico como un observador mecánico, una suerte de cine de "rescate" de un mundo que parecía desvanecerse.

Así como los instrumentos de mayor precisión nos han enseñado más sobre el cosmos, un buen registro de estos preciosos documentos culturales puede iluminar nuestro conocimiento y nuestra apreciación de la humanidad (Mead, [1974] 2003, p. 10, la traducción es propia).

A partir de la llamada "crisis de la representación" en antropología-desde mediados de los años 1970-, nuevas voces empezaron a cuestionar estos usos de la cámara, poniendo en discusión la supuesta autenticidad de su registro o, mejor, poniendo en evidencia el juego de artificios en la construcción del relato audiovisual, el establecimiento de relaciones de poder asimétricas que se generaban a través del cine y la imposición de discursos sobre 
un "otro" generalmente mudo, en el seno una disciplina nacida desde las entrañas del proyecto colonialista de occidente (Piault, 2000; Ruby, 2000; Rony, 1996; Nichols, 1997). A lo largo de estos vaivenes -entre la reflexión crítica, la producción acrítica y la experimentación absorta-, distintos antropólogos se aproximaron al audiovisual incorporando la figura del filmmaker ${ }^{2}$ a la disciplina, para fundar, entre límites difusos y múltiples confluencias, lo que denominamos antropología visual ${ }^{3}$. La cámara se impuso como una herramienta para el estudio antropológico, y el filme -hijo menor del texto académico- comenzó a reclamar un mayor estatus (Mead, [1974] 2003; Ruby, 1991). En ese devenir se fue creando un espacio de reflexión sobre el registro de la imagen y el sonido y sobre las relaciones sociales -actuales e históricas- que se tejen en la fabricación de estos registros.

La antropología visual incorporó progresivamente nuevas perspectivas e intereses para discutir los vínculos que se establecen en la construcción de las imágenes sobre los "otros" -fijas o en movimiento, con o sin sonido-, para ir de a poco disolviendo las distancias entre el sujeto investigador y los sujetos investigados. Asimismo, la cámara irá cambiando de manos, para registrar imágenes construidas por los "otros" y con los "otros". Un punto de partida posible a esto ha sido la iniciativa comandada por Sol Worth, John Adair y Richard Chalfen, cuando en junio de 1966 les enseñaron a los navajos (diné) a utilizar cámaras de 16 mm (Worth y Adair, 1970 y 1972). Sin embargo, más allá del hito inaugural que significó esa experiencia, lo que ocurrió no dejó de ser un hecho aislado sin un desarrollo inmediato posterior. En Latinoamérica, en cambio, el uso del video por parte de indígenas surgió como un movimiento social y asumió en muchos casos una posición política crítica, con miras a la autodeterminación y a la revitalización cultural; bajo la denominación "video indígena"4 se formó una importante corriente en torno a la reali-

2 Término que Jean Rouch prefería al de realizador, ya que conjugaba la tarea del etnocineasta, que trabaja solo, sin equipo (Colleyn, 2004, p. 387).

3 También denominada antropología audiovisual. Conservo aquí el adjetivo visual, debido a que posee una mayor profundidad histórica y, por ello, brinda la posibilidad de rastrear sus antecedentes.

4 No hay un término unificado que haga referencia a la apropiación de herramientas audiovisuales por parte de los indígenas. En Brasil, por ejemplo, se habla de vídeo índio (Carelli, 2011); en Estados Unidos, de indigenous media (Ginsburg, 1991), y en México, de video indígena (Wortham, 2013). En Nueva Zelanda, los maoríes hablan sencillamente de cine (Gauthier, 2008), aunque es cierto que sus realizaciones son más cercanas al cine industrial. Como alguna vez dijo Claude Chavrol, "un cinéaste ne mérite ce nom que du moment où il sait qu'il fait" (Aumont, 2011). En ese sentido, el término "cine" puede ser anclado en un saber, una decisión o una puesta en marcha de un proyecto cinemato- 
zación audiovisual a lo largo del continente americano (Salazar y Córdova, 2008; Wortham, 2004 y 2013; Salazar, 2009; Schiwy, 2009; Córdova, 2011; De Cavalho et al., 2013; Soler, 2017; Zamorano Villareal, 2009).

Me interesa analizar aquí la experiencia de la realización cinematográfica como proceso en el que las concepciones sobre el cine y el quehacer antropológico se desplazan y transforman. Este análisis busca dejar de lado una noción de cine sobre los otros, o realizado por los otros, para pensar el espacio del audiovisual como un medio de interacción social y política, intercultural.

\section{Media-médium}

Buena parte de los antropólogos han logrado liberarse de una forma hiperdescriptiva de realizar etnografía, que proponía reforzar el distanciamiento entre el investigador y el investigado, y en la que la cámara, en la búsqueda de una objetividad cientificista, servía para profundizar ese distanciamiento. Una de las figuras claves en esa ruptura fue el antropólogo y cineasta Jean Rouch, quien mostró total libertad en sus filmes; "manipulaba las secuencias para crear no un filme de investigación, sino una verdadera obra cinematográfica; sabía hacer uso del trance que el propio filmar provocaba" (Boudreault-Fournier et al., 2016, pp. 38-39; la traducción es propia). En su clásico filme Les Maîtres Fous (1955), la cámara parece entrar en trance y disolver las distancias entre quien la opera y quienes son filmados, y permite -cámara-medium-que ingresen en escena también los espíritus, vivos y muertos. A partir de esta idea y de esta gravitación de imágenes concebí el título de este artículo, Media-médium, con el que busco indagar sobre el cine y las diferentes dimensiones de lo social que entrelaza, no enfocándome en la cámara y su operador, sino en el proceso mayor de abordar un proyecto comunitario catalizado por la realización cinematográfica.

A través del relato de una serie de experiencias vividas durante mi trabajo de campo etnográfico, sugiero posibles vías de exploración de las dimensiones del cine como experiencia, más allá de la materialidad de la obra producida. Estas dimensiones de lo social que surgen en el quehacer cinematográfico tienen que ver con cómo se construyen los vínculos al interior

gráfico lo que abre un espacio amplio desde el punto de vista creativo. Igualmente, no descuidamos las importantes raíces históricas del término "video indígena" en el contexto latinoamericano. 
de cada comunidad con la que se trabaja, las relaciones entre grupos de edad y los roles de autoridad que se manifiestan y que habilitan o no la posibilidad de la realización audiovisual. Esto será ejemplificado a través de dos experiencias distintas, de las que se narran los momentos de la singular concepción de los guiones y del rodaje. Por otro lado, se plantea que más allá del corte final de una película, el filme puede concebirse como abierto o inacabado, en constante proceso de construcción, como una obra que se transfigura y deviene performance en una proyección, y que implica la puesta en acto de sensibilidades, decisiones estéticas e imaginarios. En este sentido, el cine como proceso en construcción, más allá de su materialidad o corte final, puede ser analizado como médium, por su capacidad de hacer entrar en contacto múltiples dimensiones de lo social y múltiples seres.

Desde 2014 he trabajado dando talleres de cine en comunidades indígenas, primero con shuar de la Amazonía ecuatoriana y, luego -desde 2015-, con indígenas del Chaco argentino, principalmente qom (tobas). He enseñado cine sola y en equipo, colaboré en rodajes comunitarios y pasé largo tiempo editando en el terreno, codo a codo con quienes se acercaban a aportar sus ideas. De a ratos ocupaba el rol de etnógrafa, tomaba notas de campo y entrevistaba a la gente sobre la experiencia de filmar y sobre los tantos otros asuntos que nos interpelaban, y luego volvía a ser un peón más en el juego del rodaje y a sostener, por ejemplo, una caña de sonido durante horas.

Generalmente, un proyecto audiovisual se aborda a partir de un guion o idea inicial; luego se pone en marcha la preproducción, se procura financiamiento y se conforma un equipo técnico, y, a continuación, se emprende la ejecución del rodaje, el montaje y la posproducción de imagen y sonido. Cuando se trata de cine comunitario e indígena, este procedimiento difícilmente tenga una forma predecible ni se dé en ese orden. El antropólogo-cineasta que se acerca al cine comunitario tiene que desaprender continuamente su manera de trabajar si pretende abrirse paso, a través de la realización cinematográfica, hacia el conocimiento, íntimo y singular, de otras maneras de vincularse. Esto implica una doble tarea: la de alejarse de las maneras aprendidas de hacer cine, y la de aprender nuevos códigos sociales y narrativos. 


\section{La construcción de un guion comunitario}

Mi experiencia de cine comunitario entre los shuar tuvo lugar en el Centro Kupiamais, en la Cordillera del Cóndor (Amazonía ecuatoriana) en el marco del proyecto Etsa-Nantu/Cámara-Shuar ${ }^{5}$. Este proyecto, coordinado por Verenice Benítez y Domingo Ankuash surgió a pedido de algunos referentes de la comunidad, quienes buscaban aprender a usar las cámaras con el fin de denunciar los abusos de las empresas extractivitas mineras y del Gobierno ecuatoriano, que violentaban a las poblaciones amazónicas de la región. A fines de mayo de 2014 llegamos allí con Verenice para dar un segundo taller de cine, tras una primera experiencia llevada a cabo en febrero de ese mismo año, en la que yo no había participado. Luego de varios días de incertidumbre y discusiones internas respecto al cine y nuestro rol en la comunidad, logramos comenzar. Los primeros días del taller, tras habernos explayado sobre el uso de la cámara y habiendo presentado un amplio abanico de géneros y estilos cinematográficos, propusimos a los alumnos que trajeran historias para realizar un primer cortometraje. Lo sorprendente fue que, al día siguiente, nadie planteó la realización de un documental sobre la difícil situación que estaban viviendo, sino que todas las historias eran relatos sobre seres no-humanos; algunos, largos y complejos; otros, tan simples como la aparición de iwianch (ser no-humano que los shuar traducen como diablo al idioma castellano). Ese día apuntamos en nuestros cuadernos cerca de diez historias que nos forzarían a improvisar rodajes de cine de ficción ${ }^{6}$ en la selva, en el marco mayor de un conflicto minero que nos convocaba y movilizaba.

El primer trabajo fue un cortometraje de 7 minutos, titulado precisamente Iwianch $^{7}$, que narra la visita inesperada de un iwianch a la casa de una mujer viuda que vivía sola con sus hijos. En esta primera experiencia, la escritura del guion narrativo fue simple, y los únicos implicados en la tarea audiovisual fueron jóvenes y adultos jóvenes, que narraron las historias tradicionales sin confrontar versiones. Patrico Taish, un líder local, nos prestó su

5 Para más información sobre este proyecto se puede visitar el sitio www.camara-shuar.org

6 Aquí es importante remarcar que la distinción entre ficción y realidad es una invención del mundo occidental, como proponen Boudreault-Fournier et al. (2016): "Esta oposición no existe en el mundo amerindio, donde los sueños, o los trances de los shamanes no se caracterizan como una no realidad" (p. 39). En este sentido, cuando hablo de ficción, hago referencia al tipo de abordaje cinematográfico que caracteriza la escritura, planificación y rodaje de este género audiovisual.

7 Filme disponible en: https://vimeo.com/102850114 
vivienda típica shuar para el rodaje y, a partir de allí, comenzó a implicarse en lo que estábamos haciendo. Tras lograr montar un primer corte comenzamos a entender qué tipo de filme podíamos lograr.

Los participantes del taller nos propusieron continuar con la historia de Tsunki, que narra los orígenes de su pueblo. Durante la tarde, y hasta avanzada la noche, conseguimos escribir un primer guion narrativo, y en pocos días nos lanzarnos a un nuevo rodaje. Al final de una de las últimas jornadas de filmación lo visitamos a Patricio, quien grabaría la voz en off. Nos sentamos al lado del fuego con Rosa, su esposa, y leí en voz alta y sin interrupciones el guion ante su escucha atenta. Cuando terminé la narración, Patricio me miró fijo y me dijo: “¿Quién te contó esta historia? Esto no es asî”. Nos relató su versión y nos habló de una viejita de más de 90 años de edad que seguramente conocería otra versión mejor todavía. Ahí nos dimos cuenta de que la distancia inicial que los adultos habían mostrado hacia el aprendizaje del cine nos había hecho descuidar su autoridad como narradores y portadores de la historia (de transmisión oral), y que las versiones de las historias serían siempre múltiples, pero aquella que debería quedar plasmada en una película tenía que ser la de la voz de alguien con la sabiduría y la autoridad para narrarla. Luego de tres semanas de trabajo, la película tuvo que quedar inconclusa.

En octubre de ese mismo año volví a Kupiamais para continuar con los talleres, esta vez con Franco Passarelli. Él me acompañó los primeros días, durante los cuales retomamos la escritura del guion. Esta vez Patricio Taish ya estaba completamente implicado en la tarea audiovisual y nos propuso varios cambios en la forma de trabajar. Pensaba que los actores con los que habíamos rodado los primeros planos de Tsunki eran muy jóvenes y no comprendían la importancia del relato; no conocían a los seres que tenían que encarnar. Entonces nos propuso invitar a otras personas y, tratando de sanar un conflicto comunitario que se había abierto -se habían generado sospechas de que el proyecto de cine podía favorecer a una facción de la comunidad y no a otra- ${ }^{8}$ incorporamos gente de otras familias. Finalmente, la abuela de 90 años nos hizo llegar su versión a través de su nieto; ésta no era la más completa que escuchamos y difería bastante de las otras, pero nadie sugirió modi-

8 Los shuar tejen sus vínculos históricamente a través de alianzas y enemistades. Comenzar a trabajar con los shuar implica que esas rupturas se manifiesten en torno a las nuevas iniciativas. Patricio, sin decírnoslo, acercó al proyecto de cine a personas que sospechaban que éste iba a beneficiar a unas familias en desmedro de otras, y así buscó pacificar los conflictos. 
ficarla en ningún sentido, así que se realizó el rodaje a partir de ella. A través de este recorrido pudimos construir comunitariamente un guion definitivo para realizar el cortometraje Tsunki Aumatsamu (El mito de Tsunki) ${ }^{9}$.

\section{Lo individual y lo colectivo. Libertad narrativa}

En enero de 2017 tuve la posibilidad de presentar avances de mi investigación doctoral en el marco del seminario Pour une anthropologie visuelle pluridisciplinaire et multimédia, organizado por Jean-Paul Colleyn ${ }^{10}$. Allí reflexioné sobre distintas experiencias de campo en torno al cine comunitario indígena, entre ellas, la experiencia con los jóvenes de la comunidad qom Paraje Maipú, en el Chaco argentino. Al finalizar la intervención, una señora del auditorio se acercó y me hizo dos comentarios sobre el filme qom que había proyectado: el primero, acerca de la dicha que veía en los protagonistas -ella consideraba que era algo que faltaba en la sociedad francesa-; el segundo, más distante y tajante, fue: “ça, pour nous, c'est bidonville" (para nosotros esto es de un barrio marginal), de lo que interpreté que ella no veía los rasgos de indigeneidad que esperaba encontrar en el cine de esos jóvenes. Con mi manejo del francés algo limitado y la certeza de que no me correspondía justificar las elecciones estéticas de los chicos de Maipú, mostré sincero asombro ante su comentario y le agradecí la intervención, sin lograr comprender qué era lo que ella esperaba de ese filme para poder catalogarlo como "indígena". Ese comentario me quedó resonando y, por un lado, me sirvió para pensar las limitaciones de una película, como producto terminado, para mostrar sus condiciones de realización; por otro, me llevó a reflexionar sobre el aprendizaje adquirido durante mi experiencia de campo, que me permitía comprender algunos vínculos sociales y agenciamientos, característicos de las comunidades qom de esa región, que se habían puesto en juego para que esa película fuera posible.

9 Filme disponible en: https://vimeo.com/157352441

10 Jean-Paul Colleyn fue mi director durante la maestría que realicé en la École Des Hautes Études en Sciences Sociales (EHESS, 2013), y sigue guiando mis estudios de doctorado desde entonces. La intervención tuvo lugar en la EHESS, París, el día 19 de enero de 2016, y se tituló: Cinéma amérindien: Une analyse à partir des expériences des peuples Shuar (Amazonie équatorienne) et Qom (Chaco argentin). 
Los jóvenes de Maipú crearon su propia forma de narrar y esa forma nada tiene que ver con indagar en el devenir histórico de su comunidad o en su condición de indígenas; eso no es algo que los interpele o sobre lo que quieran reflexionar en sus videos. En un comienzo nos propusieron hacer un remake de un videoclip de una banda de k-pop (música pop de Corea del Sur) que ellos escuchan, pero luego transformaron esa idea y la hibridaron con una narrativa propia. El proceso de guionado fue muy diferente al de los shuar (se puede decir que, entre los qom, la confrontación no forma parte de su manera vincularse), y los adultos no participaron. En los primeros encuentros notamos que los jóvenes se sentían intimidados cada vez que les pedíamos que hicieran propuestas, por lo que fue necesario encontrar referentes al interior del grupo que bocetaran los guiones en sus casas; luego, durante el rodaje, se irían transformando con los aportes de todo el equipo. En Maipú trabajé junto con Eugenia Mora, y aprendimos que nuestra presencia como adultas y rokshe (blancas o "criollas") imponía una distancia que era muy difícil de soslayar, y que para que los jóvenes pudieran tener la libertad de narrar lo que quisieran, era necesaria esa distancia respetuosa; ellos mismos se acercarían a nosotras en la medida que necesitaran consejos. Aprendimos también que de esa manera se construyen los vínculos en las comunidades qom: los adultos y ancianos observan a los jóvenes, pero no imponen ni regulan conductas; están allí, en un segundo plano, para aconsejar.

El cortometraje que realizaron los jóvenes de Paraje Maipú se llama $E l$ sueño y es una ficción que narra el recorrido de Ramiro, un muchacho que se despierta solo en una cama, enciende el televisor y se ve a sí mismo bailando junto con sus hermanos y sus primos. Movilizado por la nostalgia, bajo el sopor del verano chaqueño, decide ir a buscar a sus amigos y los encuentra realizando actividades de su vida cotidiana.

La escritura del guion fue cobrando forma colectiva, ya que Romina, quien había preparado un primer boceto de la historia, propuso un esquema flexible para que cada quien, al momento de decidir cómo aparecería frente a la cámara, lo fuera modelando y modificando. Por ejemplo, Lía es una de las chicas más grandes del grupo y se caracteriza por su timidez; ella no baila, sino que participa buscando nuevos videos y descubriendo coreografías. Es experta en cestería qom, y Romina pensó que Ramiro la podría encontrar fabricando cestos. Filmaron unos hermosos planos en los que ella salía sentada, con su pelo suelto, trabajando. A mi parecer, ese personaje ofrecía al filme un interesante contrapunto, ya que no se habían elegido otras activi- 
dades que hicieran referencia a costumbres u oficios típicamente indígenas. Lamentablemente, Lía manifestó que no le gustaban esas imágenes, y sus compañeros -lejos de querer convencerla de seguir en esa línea- la ayudaron a planificar otras escenas. Todas estas modificaciones sobre la marcha fueron tomadas con total naturalidad por Romina, que apuntaba los cambios en su cuaderno, sin preocuparse por defender una posición de autora.

La historia del cortometraje tiene un desenlace enigmático: una vez que todos los jóvenes se reúnen en torno a una fogata, Ramiro le muestra a una compañera una foto del grupo y se pregunta: “¿Será que volveremos a bailar?". La escena siguiente es un plano picado que gira sobre su eje y muestra a todos los personajes durmiendo. A medida que se van despertando, van saliendo, corriendo, por una puerta. Un tema de k-pop comienza a sonar y todos van hacia el atardecer en un plano a contraluz; corren alegres, celebrando el estar juntos.

Volviendo a la pregunta de la asistente al seminario, una respuesta posible a su interrogante estaría en cómo este filme fue realizado: su planificación y su edición final se llevaron a cabo en un ambiente de apertura a las propuestas y a los consejos mutuos, característico de los qom de esa región, lo que derivó en una forma singular de trabajo. Pero la respuesta podría ser mucho más amplia y compleja si hacemos referencia a que las comunidades que viven en esa zona se asentaron allí en tiempos en que funcionaba el ingenio azucarero Las Palmas del Chaco Austral ${ }^{11}$. Las poblaciones indígenas de la región, que venían siendo desplazadas por las avanzadas militares de la llamada Conquista del Desierto ${ }^{12}$, pasaron a ser la mano de obra barata en la explotación de la caña de azúcar, y dividieron su tiempo entre la zafra estacional y la caza y la recolección que practicaban en el monte, que aún no se había talado para la explotación agrícola. Cuando en los años 1970 el ingenio comenzó su largo proceso de quiebra, las familias que trabajan en una

11 El ingenio fue fundado por los hermanos Richard y Charles Hardy en 1882. Estos colonos, como concesión del Gobierno nacional, obtuvieron 100000 hectáreas de territorios en los que habitaban comunidades indígenas.

12 A diferencia de lo que ocurrió en la mayor parte de los países latinoamericanos, Argentina se construyó como Estado nación a partir de un discurso de borramiento de los indígenas; hubo una operación de tachado, de negación. Como afirma Miguel Bartolomé (2003), "el mito de un inmenso territorio ‘desierto' y sólo transitado por unas cuantas hordas de cazadores 'bárbaros' ha sido particularmente grato a la historiografía argentina, en tanto fundamentaba el modelo europeizante bajo el cual se organizó el proceso de construcción nacional". (Ver también Briones, 2004; Lenton, 2005; Ramos, 2009). 
estancia denominada Las Coloradas empezaron a ser perseguidas violentamente. Sus viviendas fueron destruidas y sus huertos arados; se les prohibió cazar y pescar en el monte, lo que los llevó a una gran crisis y a una terrible hambruna. En ese marco surgió la figura de un líder llamado Mateo Quintana. Quintana se hizo al evangelismo y empezó a predicar y a tener visiones sobre un futuro mejor; comenzó a tener sueños sobre nuevas tierras donde se instalarían y conseguirían bienes característicos de los hombres blancos. Los que siguieron las visiones de este líder se instalaron en Paraje Maipú, que para ellos es la tierra prometida. El tiempo presente es el tiempo de la concreción de las predicciones de Quintana, las que se siguen materializando. Quintana visionó que tendrían una escuela, luz, agua; llegaría gente que hablaría otras lenguas, llegaría gente que les enseñaría nuevas tecnologías. Según nos explicaron los adultos, ellos entienden que nuestro trabajo forma parte de esas predicciones, y que los jóvenes son una generación capaz de aprender nuevos saberes y de abrirse al mundo de los blancos. Los adultos han pasado por el sufrimiento del trabajo forzado en la zafra, de la persecución militar, de la incertidumbre constante, y ven en los jóvenes la concreción de la promesa de una vida nueva, en un sentido material y espiritual. Que los jóvenes de Maipú nos convoquen para aprender a filmar, y que filmen sin ninguna imposición con respecto a qué historias son las que deben narrarse, o a las historias que narraríamos los antropólogos, es algo que guarda estrecha relación con cómo esa comunidad entiende su devenir histórico y vive su vida comunitaria.

\section{La película incompleta}

Algunas historias narradas a través de este cine ingresan en una dinámica que les quita el estatus de obra acabada. Cuando terminamos de rodar Tsunki Aumatsamu, pasé varios días en la comunidad para intentar editar un primer corte en el terreno y para discutir con la gente sobre qué forma le daríamos al filme. Fueron días de fiebre y de problemas de salud tras el cansancio del rodaje. Varias personas iban a visitarme a la casa de los Ankuash, donde me hospedaba, y me ofrecían comida y medicamentos; yo les mostraba los avances de la edición. Un día de lluvia, un familiar vecino se sentó en la galería a conversar con las mujeres de la casa. Las charlas en lengua shuar me mantuvieron un poco al margen hasta que alguien me explicó que hablaban sobre 
la historia de Tsunki. Como a la película aún le faltaba mucho trabajo para ser mostrada, este señor me pidió que le contara lo que habíamos filmado. Narré la versión tal cual la habíamos guionado, esperando una respuesta que aportara alguna nueva idea para el montaje. Cuando terminé, el hombre hizo un silencio y largó una larga carcajada. Me dijo: “¿Quién contó esa historia?; tengo una abuela que me la explicó de otra manera". Entre el cansancio y la fiebre recuerdo este episodio más como una pesadilla que como una anécdota divertida. Por la tarde vinieron Rosa y Patricio a verme y a ofrecerme una chicha curativa. Les conté lo que había pasado y Patricio me dijo de manera muy calma: "Sería bueno conocer la historia contada por esta otra abuela". En ese momento me di cuenta de que la película nunca estaría acabada, en la medida en que seguiría imbricándose con otros relatos orales e imágenes sobre el relato. Siempre habría nuevas versiones para narrar, nuevas interpretaciones y nuevas formas de concebir a los personajes -seres no-humanos corporizados por actores-. Las nuevas versiones posibles de la historia nos hicieron repensar las elipsis de la película y los espacios en los que lo narrado con la imagen sería reemplazado por la voz en off de Patricio, que atravesaría todo el filme. Registrar esas imágenes en movimiento, grabar esas voces y esos sonidos y darles un orden, un tono y una cadencia impulsaron nuevas dinámicas que aportaron otros sentidos a los relatos orales.

Quizá, a partir de esta película, los shuar de Kupiamais comiencen a concebir a Tsunki con otro aspecto, a otorgar al Tsunki padre la mirada noble de Patricio Taish, con su sonrisa siempre delineada. Tal vez estas imágenes puedan abrir el campo a nuevas historias, narradas por los que estén y con los que ya se fueron. Imagen y sonido se articulan. El sonido, siguiendo a Ong (2006), "da acceso a la interioridad de algo sin violarlo", y posee un carácter "armonizador" por oposición al carácter "discriminador" de la vista. "La vista aísla; el oído une. Mientras la vista sitúa al observador fuera de lo que está mirando, a distancia, el sonido envuelve al oyente" (Ong, 2006, p. 75). Estos dos elementos se articulan al interior del filme y se dinamizan con la oralidad pura que dispara imágenes en la interioridad de la gente. La imagen audiovisual tiene esa capacidad de maravillarnos, de afectarnos, de movilizar procesos de identificación con la imagen.

Cuando con Eugenia Mora comenzamos a dar clases de cine a algunos adultos en Paraje Maipú, mostramos un cortometraje paraguayo denominado Karai norte, a fin de explicar los distintos tipos de planos y el raccord que se establece en el montaje. Al terminar la proyección y encender la luz, 
una de las señoras asistentes nos miró con un gesto asustado y nos dijo: "Ese hombre en la película era Nowet, el dueño del monte" (Cordeu, 1969-1970). Las imágenes del cine se asocian a los imaginarios de los espectadores. El cine comunitario fuerza los límites de los cuatro vértices del rectángulo de la pantalla. Cuando en 2011 se estrenó La nación oculta, reconocida como la primera película de ficción producida por indígenas chaqueños ${ }^{13}$, se realizó una celebración en la que participaron pueblos indígenas de distintas regiones; hubo ceremonias rituales y se homenajeó a los actores y a los realizadores. La materialidad de filme, sus aciertos o problemas, quedaron al margen durante el emotivo acto -en el que hubo lágrimas y cantos-. La película se completó en esa ceremonia performática de la que ahora, para quienes la vivimos, es indisociable.

\section{Reflexiones finales}

Antropología compartida, proponía Rouch. Hoy, muchos realizamos cine compartido y, desde allí, repensamos la antropología y el cine, en ese quehacer en el que los roles autorales y el orden de los procedimientos se desdibujan para ser reinventados en el marco de nuevas prácticas cinematográficas. Con este recorrido sobre algunas experiencias en torno a la realización cinematográfica indígena, mi intención fue la de abrir un espacio de reflexión para abordar el cine en el marco social en el que se gesta; la apropiación de los medios por los pueblos indígenas de Latinoamérica expande la reflexión en torno al audiovisual. Faye Ginsburg propone que los medios indígenas, junto con el cine etnográfico, "intentan comunicar algo sobre esta identidad social o colectiva que llamamos 'cultura', a fin de mediar (eso se espera) a través de las brechas de espacio, tiempo, conocimiento y prejuicio" (1991, p. 104; la traducción es propia). La cualidad de la etnografía como experiencia sensible de acompañamiento nos permite dejarnos atravesar por otras maneras de habitar este mundo, y nos ofrece, desde allí, otras dimensiones de lo cinematográfico.

Asimismo, con este recorrido busqué visibilizar algunas cuestiones de este mundo globalizado que interpelan a los indígenas. Entre los shuar, la

13 Esta película es el producto de una serie de talleres que desde 2008 dictó el Centro de Formación y Realización Cinematográfica de Bolivia (CEFREC) en el marco de los festivales de cine indígena que se organizaron desde la Dirección de Cine de la provincia de Chaco (ver Soler, 2017). 
elección de no realizar un cine de lo inmediato - de denuncia- sino de lo remoto, nos lleva a reflexionar sobre la urgencia de plasmar esas historias tradicionales, no al modo de un cine de rescate, sino como una respuesta al avance de los intereses del proyecto moderno, que busca borrar las singularidades de las poblaciones y desterrar a todos aquellos que no alimenten un sistema económico predatorio. Tal vez las ficciones shuar operen como una nueva vía para transmitir estas historias y seguir reinventándolas. Por otro lado, acompañar procesos de aprendizaje de cine en comunidades indígenas implicó para mi dejar de lado los prejuicios colonialistas de qué es lo que los "otros" deberían filmar y cómo deberían hacerlo. La libertad narrativa de los jóvenes qom de Paraje Maipú permitió que registraran todo lo que un etnógrafo jamás filmaría en el campo; ellos recortan su entorno, su vínculo con los adultos, su forma de habitar el espacio, e hibridan sus hábitos y paisajes con estéticas del globalizado k-pop. Esta libertad se construye desde un ethos $^{14}$ indígena de la no imposición.

\section{Bibliografía}

Bartolomé, M. (2003). Los pobladores del "Desierto" genocidio, etnocidio y etnogénesis en la Argentina. Cuadernos de Antropología Social FFyL-UBA, $17,162-189$.

Bateson, G. (1958). Naven, a survey of the problems suggested by a composite picture of the culture of a New Guinea tribe drawn from three points of view. Stanford, California: Stanford University Press.

Bateson, G., \& Mead, M. (1942). Balinese character, a photographic analysis,. New York: The New York academy of sciences.

Boudreault-Fournier, A., Satiko Gitirana Hikiji, R., \& Caiuby Novaes, S. (2016). Etnofiçao: uma ponte entre fronteiras. En A experiência da imagem na etnografia (pp. 37-58). São Paulo: Terceiro Nome.

14 Gregory Bateson, en su obra Naven ([1936] 1958), introdujo el término griego ethos por primera vez en la antropología. El sentido aristotélico se refiere al tono predominante de los sentimientos de las personas en una comunidad. Bateson utiliza este término para hacer frente a lo que llamó "configuraciones" culturales, y lo asocia con su complementaria eidos. Geertz (1957), en una línea similar, y teniendo en cuenta su complementaria wordwide, retoma el término ethos haciendo referencia al tono, el carácter y la calidad de su vida, su estilo moral y estético y la disposición de su ánimo. Se trata de la actitud subyacente que un pueblo tiene ante sí mismo y ante el mundo que la vida refleja (Geertz, 1957). 
Briones, C. (2004). Construcciones de aboriginalidad en Argentina. Société Suisse Des Américanistes / Schweizerische Amerikanisten-Gesellschaft, (Bulletin 68), 73-90.

Colleyn, J.-P. (2004). Jean Rouch, presque un homme-siècle. L Homme, (171-172), 537-541. https://doi.org/10.4000/lhomme.25007

Cordeu, E. J. (1969). Aproximación al horizonte mítico de los tobas. Runa, XII partes 1-2, 67-173.

Córdova, A. (2011). Estéticas enraizadas: aproximaciones al video indígena en América Latina. Comunicación Y Medios. Universidad de Chile, 24, 81-107.

De Carvalho, A., De Carvalho, E. I. de, \& Carelli, V. (2011). Vídeo nas aldeias, 25 anos: 1986 - 2011. (Video nas Aldeias (Project), Ed.). Olinda, PE, Brasil: Vídeo nas Aldeias.

Ginsburg, F. (1991). Indigenous Media: Faustian Contract or Global Village? Cultural Anthropology, 6(1), 92-112.

Lenton, D. (2005). De centauros a protegidos. La construcción del sujeto de la política indigenista argentina desde los debates parlamentarios (1880 1970). Universidad de Buenos Aires, Buenos Aires.

Mead, M. (2003). Visual Anthropology in a Discipline of Words. En P. Hockings (Ed.), Principles of Visual Anthropology (2nd ed.). Berlin ; New York: Mouton de Gruyter.

Nichols, B. (1997). La representación de la realidad: cuestiones y conceptos sobre el documental. (J. Cerdán \& E. Iriarte, Trans.). Barcelona: Paidós.

Ong, W. J. (2006). Oralidad y escritura: tecnologías de la palabra (1. ed). México, D.F: Fondo de Cultura Económica.

Piault, M. H. (2000). Anthropologie et cinéma: passage à l'image, passage par l'image. Paris: Nathan.

Ramos, A. R. (2009). O indigenismo na montagem da naçao. Contrastes e converências entre Brasil e Argentina. Anuario Antropológico/2007-2008, 27-59.

Rony, F. T. (1996). The third eye: race, cinema, and ethnographic spectacle. Durham, NC: Duke University Press.

Rouch, J. (1955). Les maîtres fous.

Ruby, J. (1991). Speaking For, Speaking About, Speaking With, or Speaking Alongside An Anthropological and Documentary Dilemma. Visual Anthropology Review, 7(2), 50-67. https://doi.org/10.1525/var.1991.7.2.50

Ruby, J. (2000). Picturing culture: explorations of film \& anthropology. Chicago: University of Chicago Press. 
Salazar, J. F., \& Córdova, A. (2008). Imperfect media and the politics of the poetics of Indigenos Video in Latin America. En P. Wilson \& M. Stewart (Eds.), Global indigenous media: cultures, poetics, and politics. Durham: Duke University Press.

Schiwy, F. (2009). Indianizing film: decolonization, the Andes, and the question of technology. New Brunswick, N.J: Rutgers University Press.

Soler, C. (2017). Enfocar nuestra trinchera. El surgimiento del cine indígena en la provincia de Chaco (Argentina). Folia Histórica Del Nordeste, 28, 71-97.

Worth, S., \& Adair, J. (1970). Navajo Filmmakers. American Anthropologist, 72(1), 9-34.

Worth, S., \& Adair, J. (1972). Through Navajo eyes; an exploration in film communication and anthropology. Bloomington: Indiana University Press.

Wortham, E. C. (2004). Between the State and Indigenous Autonomy: Unpacking Video Indígena in Mexico. American Anthropologist, 106(2), 363-368. https://doi.org/10.1525/aa.2004.106.2.363

Wortham, E. C. (2013). Indigenous Media in Mexico: Culture, Community, and the State. Londres: Duke University Press.

Zamorano Villarreal, G. (2009). Reimagining Politics: Video and Indigenous Struggles in Contemporary Bolivia. New York University, New York.

\section{Filmografía}

Pueblo shuar (2014). Iwianch [HD]. Etsa-Nantu/Cámara-Shuar. Disponible en: https://vimeo.com/102850114

Pueblo shuar (2015). Tsunki aumatsamu, el mito de Tsunki [HD]. Disponible en: https://vimeo.com/157352441

Fecha de recepción: 19/06/2017; fecha de aceptación: 31/07/2017;

fecha de publicación: 01/09/2017 